\title{
Prevalence of problem gambling in an employed population in Brittany, France
}

\author{
Matthieu DEZUTTER ${ }^{1}$, Morgane GUILLOU-LANDREAT ${ }^{2}$, \\ Jean-Dominique DEWITTE ${ }^{1,3}$, Serge BOUZARD ${ }^{4}$, Jean-Baptiste FAUCHERON ${ }^{5}$, \\ Brice LODDE ${ }^{1}$ and Quentin DURAND-MOREAU ${ }^{6 *}$
}

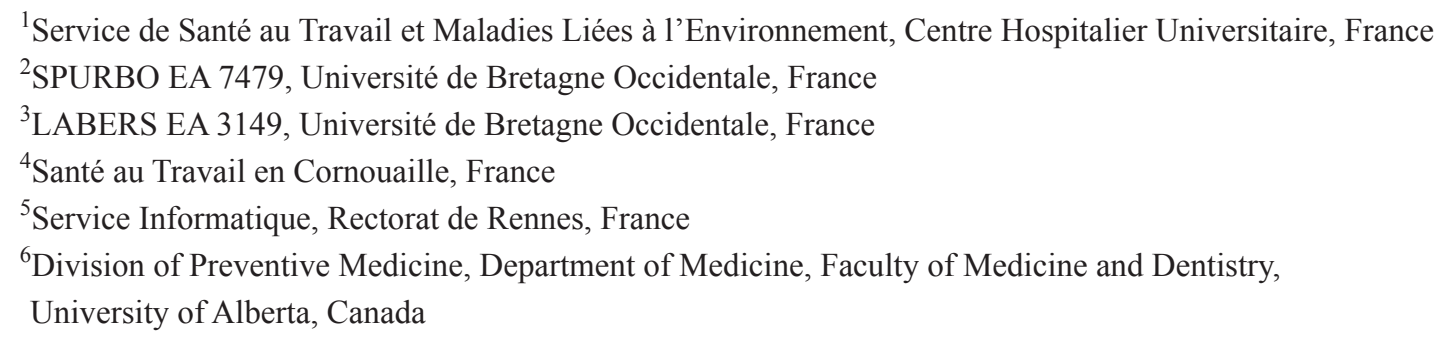

Received December 26, 2018 and accepted June 6, 2019

Published online in J-STAGE June 29, 2019

\begin{abstract}
Some employees may have recourse to gambling, notably as an adaptive strategy. Although many studies have been performed on specific occupational groups (i.e. gambling industry, transportation or teaching), none have been conducted with workers followed-up by Occupational Health Services (OHS). Our aim was to evaluate the prevalence of problem gambling in an employed population and its links with work. We performed a cross-sectional study between November 2016 and April 2017, in an OHS in France. We evaluated the prevalence of gambling using the Lie or Bet questionnaire and the Canadian Problem Gambling Index. Among the 410 employees included, $138(33.7 \%)$ had gambled in the previous year, $12(2.9 \%)$ considered their gambling experience to be work-related, $13(3.2 \%)$ were identified as problem gamblers. The influence of colleagues and the workplace hierarchy and ease of access to gambling (in tobacco shops, bars...) could be risk factors. Screening for gambling behavior could be offered by occupational health services, using the Lie or Bet, especially for employees exposed to readily available gambling opportunities at their workplace.
\end{abstract}

Key words: Occupational health services, Occupational diseases, Addictive behavior, Gambling, Workplace

\section{Introduction}

Gambling is a widespread social activity worldwide. Calado and Griffiths showed in a review that all national surveys concluded that there were more gamblers than

*To whom correspondence should be addressed. E-mail: durandmo@ualberta.ca

(C)2020 National Institute of Occupational Safety and Health non-gamblers ${ }^{1)}$; for example, $75 \%$ of males and $71 \%$ of females had gambled in the previous year in the $\mathrm{UK}^{2}$, and $74 \%$ of the general population in France had gambled in the previous year ${ }^{3)}$. Social gambling defined as gambling without loss of control and without damages, may become a pathological gambling in a minority of cases ${ }^{4,5)}$. Pathological gambling is a behavioral addiction first characterized in the DSM-IV by a loss of control over gambling which then becomes the subject's only interest, prevailing 
over all her or his other activities, causing serious harmful consequences to social, family, or financial life. Prevalence studies found a $1.6 \%$ lifetime prevalence of pathological gambling and a $3.8 \%$ prevalence of lifetime problem gambling in Northern America in 2000 ${ }^{6}$. Gambling classifications have changed with the DSM- $5^{7}$. Gambling disorder (GD) includes several levels of gambling behaviors severity from problem gambling to pathological gambling. Severity of the GD increases with the accumulation of DSM- 5 criteria met by each patient ${ }^{6)}$.

Links between social gambling and GD are not linear and different factors-individual and environmental factors or behavioral characteristics linked to gamblingmay influence gambling status and the development of the gambling behavior ${ }^{1)}$. Problem gambling (PG) is more likely to occur among men ${ }^{1-3,8)}$, with psychiatric disorders ${ }^{8)}$, or individuals of extreme age ${ }^{9-12)}$. Environmental factors, such as level of income, socio-economic integration, or social support and working status have an influence, both on PG prevalence worldwide and on an individual's gambling trajectory between social gambling and $\mathrm{GD}^{1,4,8)}$. Income is more associated to engagement with gambling rather than problem gambling ${ }^{13)}$.

All of these factors may help to identify occupational groups that could be more likely to gamble (i.e. occupational sectors with high incomes, attracting men or relative youth $^{14)}$ ). Indeed, key drivers of gambling include social influences, which comprise influence (either negative or positive) from colleagues at the workplace ${ }^{15,16)}$. Being surrounded by gamblers normalizes gambling behavior.

In the field of occupational medicine and health, the issue of addictive disorders, including gambling disorders, is attracting growing interest ${ }^{17}$. Data from the 2007 British Gambling Prevalence Survey have shown that household occupational category was significantly associated with problem gambling ${ }^{13)}$. Some existing studies on gambling have been performed in specific occupational groups. Belonging to a specific occupational group may also influence ways of gambling (e.g. horse race betting at the track vs. street betting) ${ }^{13)}$.

Several studies have focused on gambling industry and casino workers ${ }^{16,18,19)}$. In a study performed in 1999, Shaffer et al. have found that the rate of pathological gambling in casino employees in the past year was significantly higher than in general populations $(2.1 \%$ vs. $1.1 \%)^{18)}$. However, the prevalence of past-year problem gambling was found to be lower among casino employees than in the general adult population. Higher rates of problem gambling among casino workers could be related to occupational exposure to gambling ${ }^{16)}$. Hing and Gainsbury have shown that reduction of social opportunities related to shift work is a risk factor for problem gambling ${ }^{16)}$. These authors have also found workplace motivators to gamble especially include job dissatisfaction.

Other occupational groups have also been studied as regards to their gambling practices. A study performed among 904 workers in an academic health center in the United States of America in 2000 showed a lifetime rate for problem and pathologic gambling of 3.0\% and $1.8 \%$ respectively ${ }^{20)}$. Phua has shown that occupational attractiveness of the profession of banking is predicted by gambling ${ }^{21)}$. A French nationwide cross-sectional study performed in 2010 has shown that teachers were less likely to gamble regularly $(\mathrm{OR}[95 \% \mathrm{CI}]=0.41[0.25-0.68])^{22)}$. In a survey performed in Norway in 2007 with workers in the transport industry, $3.2 \%$ were identified as problem gamblers vs. $0.7 \%$ in the general population, using the same scale (NORC DSM Screen for Gambling Problems, NODS $)^{23)}$.

However, no recent data are provided in the French workforce concerning problem gambling. Occupational Health Services (OHS) offer opportunities to screen for work-related issues in the French working force. Any employed worker must be offered OHS, paid by her or his employer, as regards to the French Labor Code. To our knowledge, no previous studies have been performed concerning problem gambling in the French workforce, screened by OHS.

Our main objective was to evaluate the prevalence of problem gambling in an employed population. In particular, we investigated in a cross-sectional study the relationship between a variety of socio-economic variables and gambling, and identified a variety of risk factors concerning the influence of work on gambling. Performing this study in an OHS should also allow to discuss feasibility of this screening in daily practice.

\section{Subjects and Methods}

We undertook a monocentric cross-sectional descriptive study between November 1, 2016 and April 30, 2017. This study took place during occupational medical consultations within an inter-company occupational health service (OHS) in Brittany (France). They were carried out by the main investigator who was an occupational physician.

An inter-company OHS is an independent structure providing the follow-up for workers and the assessment for their fitness for work. It is mandatory for all enterprises 
to provide an independent OHS. Small and Medium enterprises are obliged to pay for an inter-company OHS. The biggest enterprises can have their own medical service. In all situations, French health and labor regulations guarantee the confidentiality of the consultation and all medical data. French occupational health professionals do practice occupational health regarding the International Commission on Occupational Health Code of Ethics ${ }^{24)}$.

All the patients who encountered the main investigator in the OHS, and who were able to understand the French language, gave their consent and were included. Reasons for not including patients were refusals and non-French speaking. For employees who encountered the physician several times during the collection period, we only included data from the first visit, in order to avoid overrepresentation.

All included patients were asked whether they have gambled or not over the past 12 months by the investigating physician during the encounter. A positive answer qualified them as gamblers.

The Lie or Bet questionnaire was completed by all included employees in the waiting room, before undergoing the interview with the main investigator. The Lie or Bet is a self-administered pre-screening tool with the two following questions ${ }^{25-27)}$ :

- Have you ever lied to your family or friends about the money you have gambled?

- Have you ever felt the need to bet more and more money?

If the patient-employee answered yes to at least one question from the Lie or Bet, the investigator then conducted the CPGI questionnaire with them during the encounter. The Canadian Problem Gambling Index (CPGI) is a nine-item questionnaire used to screen for problem gambling, 28).

Each item is rated on a 4-point Likert scale. The final score is the sum of all items. A score greater than or equal to 3 corresponds to moderate risk gambling and a score greater than or equal to 8 corresponds to problem gambling.

Each employee who admitted to having gambled during the past year was asked the question do you think there is a link between your gambling and your work? For all positive answers, a short description of the clinical situation was recorded in writing by the main investigator. Gambling type over the past 24 months was collected by the main investigator during the encounter. No precise estimation as regards to

the levels of gambling for each reported type of gambling by the patient was performed.
The main criterion was the prevalence of problem gambling, defined as all the gamblers rated as being at moderate or excessive risk, according to the CPGI. The secondary criteria evaluated were the types of gambling and the proportion of gamblers who linked their gambling to their job. A short abstract of each clinical situation of these patients was written by the investigator.

The employees' socio-demographic data collected during the consultation included age, gender, level of education, employee contract (fixed-term contract, permanent contract, interim, or seasonal), the profession according to the INSEE classification of Professions and Socio-professional Categories (PCS 2003), and the company's business sector according to the French Nomenclature of Activities (NAF 2008, 2nd revision). A descriptive analysis of the socio-demographic data of the employees and gambling characteristics was carried out in order to obtain means, medians and standard deviations for continuous variables, as well as the number of people and percentage for categorical variables. A comparative analysis completed the statistical analysis. The socio-demographic data of the employees who took part in the study were compared to those of other employees, working in the same sector, who also consulted the occupational physician. These anonymous data were obtained by extraction from the STETHO ${ }^{\circledR}(2012$ R3) software of the occupational health service. Frequency comparisons were performed using $\chi^{2}$ tests, or the Fisher exact tests when the theoretical numbers were less than or equal to 5. Mean comparisons were done using Student $t$ tests. The alpha risk was set to 0.05 . Statistical analyses were performed with R software $(\times 64$ 3.4.0).

The study has been approved by the ethics committee of the University Hospital of Brest on September 29, 2016.

\section{Results}

We included 413 employees seen in consultation by the investigator between November 1, 2016 and April 30, 2017. Figure 1 shows the flowchart of the study and the number of gamblers, i.e. people with a positive Lie or Bet score and problem gamblers according to the CPGI, as well as the distributions by type in the different populations. The proportion of problem gamblers was $3.2 \%, 95 \% \mathrm{CI}[1.5$, 4.9]. The socio-demographic characteristics of the included population, the gamblers, people with a positive Lie or Bet score and problem gamblers are presented in Table 1.

The most represented socio-professional category was that of employees. These include 70 commercial employees (PCS 2003 code 55, including sellers in most 


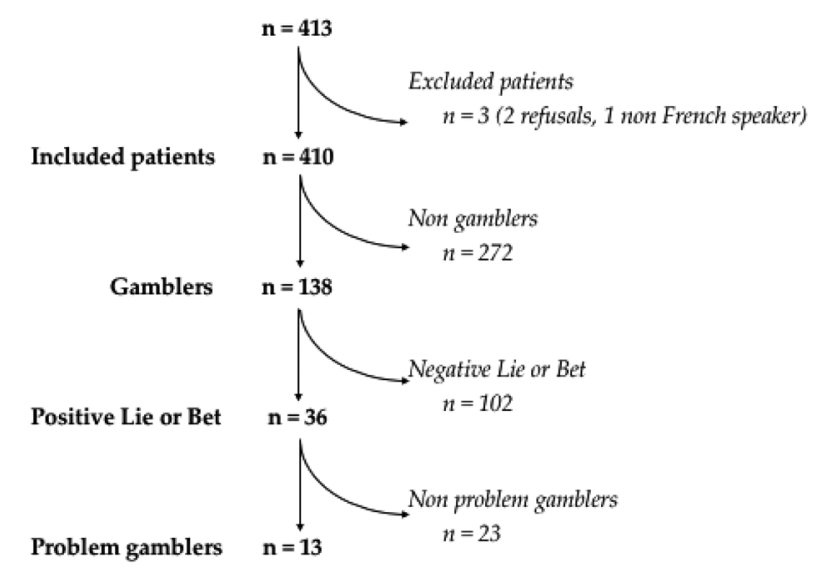

Fig. 1. Flow chart.

shops and grocery stores) and 60 personnel in direct customer services (PCS 2003 code 56, including hotel workers, housekeepers, babysitters...). The activity sector "Wholesale and retail trade; motor vehicle and motorcycle repairs" is the most represented.

The types of gambling practiced by the gamblers with a positive Lie or Bet score and problem gamblers are presented in Table 2. The games most played by gamblers are scratch games. Among the gamblers, $12(8.7 \%$ of gamblers) linked their gambling to their work. Of these, 5 (3.6\%) had a positive Lie or Bet result and only one was a problem gambler. The others were not problem gamblers.

Abstracts concerning each clinical situation of these gamblers are reported in Appendix 1.

\section{Discussion}

According to Durand-Moreau et al. ${ }^{29)}$, the question of screening for the use of psychoactive substances often takes priority over the understanding of the physio-pathological phenomena and the pathogenic role that occupation can play. This helps to explain why occupational physicians are more interested in the issue of substances with a psychoactive effect compared to non-substance addictions, with the notable exception of workaholism ${ }^{29,30)}$.

Our study found a prevalence of problem gamblers of $3.2 \%$ in the employed population examined. This figure is similar to the global prevalence estimated in an Inserm report in 2008, in the French general population, in which from $1.5 \%$ to $3 \%$ were deemed to be problem and pathological gamblers ${ }^{31)}$. In 2014, Costes measured the prevalence of problem gambling at $2.7 \%^{32)}$. We used the same tool (CPGI) and the same definitions of problem gambling as Costes.
In our study, hazardous games are the most represented (scratch games, lotteries and casinos). These are characterized by a short waiting time between the bet and the win, strong potential for repetition or potential for immediate winning, with potential for strong positive reinforcement. We find a statistically significant association between level of education and being a gambler ${ }^{31)}$. As described in disorders linked to substance use ${ }^{33)}$, failure at school is described as a risk factor and, in contrast, good integration at school as a protective factor. Nyman et al. have demonstrated that academic difficulties are a risk factor for pathological gambling ${ }^{34)}$.

Hypotheses about the links between work and gambling behavior

In our study, twelve gamblers linked their occupation and their gambling. The clinical histories (Appendix 1), collected during the consultations, make it possible to outline different propositions concerning the influence of work on gambling. However, these links are just hypothetical and based on the clinical material. A crosssectional design does not allow drawing conclusions on any causality link. But we decided to share both clinical abstracts and our hypothesis in order to initiate pathways for further researches.

Influence of work colleagues

Four people from different socio-professional categories admit gambling with their colleagues (sports betting or participation in lottery super-jackpots). Some authors have shown the influence of peers on gambling ${ }^{31,33)}$. Two patients reported that this activity was important for strengthening team spirit. According to Burlacu, problem gamblers are more sensitive to the activities of friends and colleagues who share the same work, with the aim of belonging to the group and socializing ${ }^{35)}$.

Influence of work hierarchy and young age

The only problem gambler who perceived links between gambling and work started to gamble during his apprenticeship. During this period, he gambled with his employer. In the majority of cases, the introduction to gambling takes place during adolescence ${ }^{31)}$. However, apprenticeship is a work situation in which adolescents are confronted for the first time with the corporate world. A study performed in Switzerland showed that, among adolescents, the problem gamblers are significantly more often apprentices with a high proportion of debt $t^{36)}$. In the situation of our study, where this apprentice gambles 
Table 1. Description of the population

\begin{tabular}{|c|c|c|c|c|c|}
\hline & $\begin{array}{l}\text { Included } \\
\text { population }\end{array}$ & $\begin{array}{c}\text { Non } \\
\text { gamblers }\end{array}$ & Gamblers & $\begin{array}{l}\text { Population with a } \\
\text { positive Lie or Bet }\end{array}$ & $\begin{array}{l}\text { Problem } \\
\text { gamblers }\end{array}$ \\
\hline $\mathrm{N}$ & 410 & 272 & 138 & 36 & 13 \\
\hline Mean age (yr) & 40.75 & 40.73 & 36.34 & 36.75 & 36.15 \\
\hline Standard deviation & 12.67 & 12.68 & 13 & 13.52 & 14.79 \\
\hline Level of education & & & $p<0.001$ & $p=0.07$ & $p=0.09$ \\
\hline No diploma or school leaving certificate & $30(7.3 \%)$ & $23(8.5 \%)$ & $7(5.1 \%)$ & $2(5.6 \%)$ & $1(7.7 \%)$ \\
\hline Vocational training certificate & $129(31.5 \%)$ & $80(29.4 \%)$ & $49(35.5 \%)$ & $13(36.1 \%)$ & $6(46.1 \%)$ \\
\hline Baccalaureate & $114(27.8 \%)$ & $62(22.8 \%)$ & $52(37.7 \%)$ & $15(41.7 \%)$ & $6(46.1 \%)$ \\
\hline 2-yr higher education qualification & $71(17.3 \%)$ & $52(19.1 \%)$ & $19(13.8 \%)$ & $5(13.9 \%)$ & 0 \\
\hline Graduate or post-graduate qualification & $66(16.1 \%)$ & $55(20.2 \%)$ & $11(8 \%)$ & $1(2.8 \%)$ & 0 \\
\hline Type of contract & & & $p=0.4$ & $p=0.7$ & $p=0.5$ \\
\hline Seasonal & $3(0.7 \%)$ & $1(0.4 \%)$ & $2(1.4 \%)$ & 0 & 0 \\
\hline Fixed-term & $65(15.8 \%)$ & $45(16.5 \%)$ & $20(14.5 \%)$ & $8(22.2 \%)$ & $4(30.8 \%)$ \\
\hline Permanent & $332(81 \%)$ & $217(79.8 \%)$ & $115(83.3 \%)$ & $28(77.8 \%)$ & $9(69.2 \%)$ \\
\hline Apprenticeship & $6(1.5 \%)$ & $5(1.8 \%)$ & $1(0.7 \%)$ & 0 & 0 \\
\hline Functionaries & $4(1 \%)$ & $4(1.5 \%)$ & 0 & 0 & 0 \\
\hline Socio-professional category & & & $p=0.3$ & $p=0.7$ & $p=0.7$ \\
\hline Artisans, shopkeepers and entrepreneurs & $5(1.2 \%)$ & $4(1.5 \%)$ & $1(0.7 \%)$ & 0 & 0 \\
\hline Managers and higher intellectual professions & $25(6.1 \%)$ & $20(7.4 \%)$ & $5(3.6 \%)$ & $1(2.8 \%)$ & 0 \\
\hline Intermediate professions & $75(18.3 \%)$ & $53(19.5 \%)$ & $22(15.9 \%)$ & $4(11.1 \%)$ & $1(7.7 \%)$ \\
\hline Employees & $196(47.8 \%)$ & $121(44.5 \%)$ & $75(54.3 \%)$ & $21(58.3 \%)$ & $7(53.8 \%)$ \\
\hline Blue collar workers & $109(26.6 \%)$ & $74(27.2 \%)$ & $35(25.4 \%)$ & $10(27.8 \%)$ & $5(38.5 \%)$ \\
\hline Business sector & & & $p=0.3$ & $p=0.4$ & $p=0.5$ \\
\hline Wholesale and retail trade; motor vehicle and motorcycle repairs & $119(29 \%)$ & $76(27.9 \%)$ & $43(31.2 \%)$ & $12(33.3 \%)$ & $5(38.5 \%)$ \\
\hline Manufacturing & $66(16.1 \%)$ & $47(17.3 \%)$ & $19(13.8 \%)$ & $6(16.7 \%)$ & $3(23.1 \%)$ \\
\hline Health \& social work activities & $66(16.1 \%)$ & $43(15.8 \%)$ & $23(16.7 \%)$ & $3(8.3 \%)$ & $1(7.7 \%)$ \\
\hline Accommodation and catering activities & $32(7.8 \%)$ & $17(6.3 \%)$ & $15(10.9 \%)$ & $5(13.9 \%)$ & $1(7.7 \%)$ \\
\hline Financial and insurance activities & $23(5.6 \%)$ & $17(6.3 \%)$ & $6(4.3 \%)$ & $1(2.8 \%)$ & 0 \\
\hline Transportation and storage & $22(5.4 \%)$ & $13(4.8 \%)$ & $9(6.5 \%)$ & $3(8.3 \%)$ & $1(7.7 \%)$ \\
\hline Professional, scientific and technical activities & $18(4.4 \%)$ & $16(5.9 \%)$ & $2(1.4 \%)$ & 0 & 0 \\
\hline Public administration and defence & $15(3.7 \%)$ & $13(4.8 \%)$ & $2(1.4 \%)$ & $1(2.8 \%)$ & 0 \\
\hline Administrative and support service activities & $12(2.9 \%)$ & $9(3.3 \%)$ & $3(2.2 \%)$ & 0 & 0 \\
\hline Education & $12(2.9 \%)$ & $8(2.9 \%)$ & $4(2.9 \%)$ & $1(2.8 \%)$ & 0 \\
\hline Other service activities & $11(2.7 \%)$ & $6(2.2 \%)$ & $5(3.6 \%)$ & $2(5.6 \%)$ & $1(7.7 \%)$ \\
\hline Construction & $6(1.5 \%)$ & $3(1.1 \%)$ & $3(2.2 \%)$ & $1(2.8 \%)$ & 0 \\
\hline Arts, entertainment and recreation & $4(1 \%)$ & $2(0.7 \%)$ & $2(1.4 \%)$ & 0 & 0 \\
\hline Real estate activities & $2(0.5 \%)$ & $1(0.4 \%)$ & $1(0.7 \%)$ & $1(2.8 \%)$ & $1(7.7 \%)$ \\
\hline Information and communication & $1(0.2 \%)$ & 0 & $1(0.7 \%)$ & 0 & 0 \\
\hline Water supply; sewerage, waste management and remediation activities & $1(0.2 \%)$ & $1(0.4 \%)$ & 0 & 0 & 0 \\
\hline
\end{tabular}

$p$-values are based on independence $\chi^{2}$ tests between each category and non-gamblers.

with his employer, the new income, the young age of the apprentice and the influence of the hierarchy (employer, adult) may lead to gambling addiction.

Difference between earning and winning

One of the gamblers described using gambling to try to improve her monthly remuneration. Indeed, Bernoulli has stated that the satisfaction of the gambler increases less and less with higher incomes. In other terms, 500 Euros of gain generate a larger utility in a poor gambler rather than in a wealthy one ${ }^{34)}$. Although interesting, this theoretical perspective has been questioned ${ }^{34,37)}$. Nowadays, according to Nyman et al., "there appears to be no consensus among economists to date as to why people gamble" (p. $\left.66,{ }^{34)}\right)$. Anyway, making money from gambling or making it from working does not have the same meaning. The 
Table 2. Results in population according to the gambling type

\begin{tabular}{lccc}
\hline & Gamblers & $\begin{array}{c}\text { Population with } \\
\text { a positive Lie or Bet }\end{array}$ & Problem gamblers \\
\hline Gambling type & & & \\
Scratch games & $64(46.4 \%)$ & $16(44.4 \%)$ & $6(46.1 \%)$ \\
Draws & $60(43.5 \%)$ & $10(27.8 \%)$ & $2(15.4 \%)$ \\
Sports betting (online or offline) & $18(13 \%)$ & $10(27.8 \%)$ & $6(46.1 \%)$ \\
Casino & $18(13 \%)$ & $12(33.3 \%)$ & $6(46.1 \%)$ \\
Poker online or offline & $6(4.3 \%)$ & $4(11.1 \%)$ & 0 \\
Point-of-sale games & $1(0.7 \%)$ & 0 & 0 \\
Gambling on the internet & $1(0.7 \%)$ & 0 & 0 \\
\hline
\end{tabular}

Percentages are calculated in row.

winnings from gambling are not obtained by the "sweat of your brow" (earned). According to Nyman et al., people who gamble are strongly influenced by the need to work to earn a salary; they see the gains from gambling, from the point of view of the labour market, as a way of gaining "something for nothing"34).

Ease of access to gambling and influence of the work environment

In the same way that the availability of psychoactive substances is a risk factor for initiation and maintenance of consumption, the availability of gambling may lead to its excessive use ${ }^{23,31)}$. Three of the gamblers are employees of bar-tobacconists', the preferred point-of-sale for gambling in France. These three people gamble using the opportunities available (scratch cards, lotteries, point-ofsale games and sports betting). For one patient, his work allowed him to diversify his gambling activity without increasing it. Another gambler described her gambling as resulting from her occupation, in order to learn about the products that she sells. Her gambling started at work during these tests. Finally, two patients only gamble in their workplace with clients. The accessibility and availability of gambling are central elements in the development mechanisms of problem gambling and influence the frequency of use and the total number of problem gamblers $^{38)}$. Among those recruited, the nature of the work itself, including the task of selling gambling products or taking sports bets, could also attract gamblers, due to the availability of gambling opportunities ${ }^{18)}$.

Ability to adapt to changes in work rhythm

The irregularity of working hours for one of the patients led to daily interruptions and her workplace was a long way from her home. Therefore, she would spend these long breaks in bar-tobacconists' and started to gamble to pass the time. Ngo Nguene showed that the self-adaptation of workers to changes in work rhythm could encourage the consumption of alcoholic drinks ${ }^{29}$. Moreover, the battle against boredom has been identified as a motivation for gambling, whether this is reactive or problematic. An irregular work rhythm could thus encourage gambling. This spare between working hours may constitute a facilitator, offering opportunities to gamble ${ }^{39)}$.

\section{Strengths and Limitations of the study}

This study is original as it concerns gambling and occupation. Anyway, the main limitation of this work is related to the small population of problem gamblers we identified. We initially included a large sample of employees. But, we also suffered from a recruitment bias. Some employed populations (farmers, sailors, civil servants, etc.) are monitored by other occupational health services. Its crosssectional nature does not make it possible to study the relative risk or to establish causal relationships. In view of the fact that the answers to the questionnaires were based on the sincerity of the individuals, it was possible for them to make their gambling activity appear smaller, resulting in a response bias. The latter element could also be one of the explanations for the absence of problem gamblers from our population (Appendix 1).

Another methodological option could have been to perform a study in a gambling reference centre. Although interesting, this possibility also leads to selection bias. Only the most severe consenting patients have a follow-up in such centers. Among the 13 problem gamblers identified in our study, only two of them benefited from a management of their gambling disorder. The others had no specific followup and thus could not be recruited in such centers.

It is important to point out that the main investigator ad- 
ministered the ICJE questionnaire (which is not designed as a self-administered one) and performed interviews with the patients himself. As he was engaged in the research, this might had an influence on the answers provided. Besides, as fitness for work is assessed in OHS, there could be a bias related to the workers' fear to be declared unfit to their job. The way they answer can constitute a social desirability bias.

\section{Perspectives}

Easy access to hazardous games (i.e., in tobacconists', casinos...) sometimes drives workers suffering from problem gambling towards theft. This raises both legal and medical issues. Regarding occupational health followup, it seems judicious to take into account the evaluation of gambling behavior, especially for those exposed to the easy availability of gambling opportunities. Detection could be achieved simply through the use of Lie or Bet. In the case of positive results on the questionnaire, the employee could be referred to a structure specialized in the treatment of gambling addiction and an occupational diseases centre to gain a deeper understanding of the links between health and work.

This study found a prevalence of problem gamblers of $3.2 \%$ in a working population. No statistical association was found between socio-professional categories or business sectors and gambling. The influence of work colleagues, hierarchy, context, the need for additional income, ease of access to gambling or adaptation to changes in work rhythm are all risk factors identified in our study.

Authors have already emphasized the interest in screening people for problem gambling ${ }^{18,20)}$. Indeed, it might be useful to detect risky gambling behavior by the Lie or Bet among workers exposed to the easy availability of gambling opportunities at their workplace, and then possibly to refer them to an addictive disorders center and the occupational diseases resource center. As social influence plays a major role in gambling behaviors, taking into consideration the workplace could be more efficient as management strategies only based on the individual ${ }^{15)}$. Interest on this prevention also resides on theft prevention in the workplace as well as prevention of debts for workers ${ }^{16)}$.

\section{Authors Contributions}

Conceptualization, QDM and MGL, Methodology, QDM and MGL, Validation, MD, QDM, BL, JD, SB, JBF, MGL, JDD; Formal Analysis, MD, JBF; Investigation, MD; Resources, MD, SB; Data Curation, MD, JBF;
Writing-Original Draft Preparation, MD; Writing-Review \& Editing, QDM, BL, JD, SB, JBF, MGL, JDD; Supervision, QDM and MGL; Project Administration, QDM.

\section{Funding}

This research received no external funding.

\section{Conflicts of Interest}

The authors declare no conflict of interest.

\section{References}

1) Calado F, Griffiths MD (2016) Problem gambling worldwide: an update and systematic review of empirical research (2000-2015). J Behav Addict 5, 592-613. [Medline] [CrossRef]

2) Wardle H, Moody A, Spence S, Orford J, Volberg R, Jotangia D, Griffiths M, Hussey D, Dobbie F (2011) The British Gambling prevalence survey 2010. The Stationery Office, London.

3) Costes JM, Kairouz S, Eroukmanoff V, Monson E (2016) Gambling patterns and problems of gamblers on licensed and unlicensed sites in France. J Gambl Stud 32, 79-91. [Medline] [CrossRef]

4) De Luigi N, Gibertoni D, Randon E, Scorcu AE (2018) Patterns of gambling activities and gambling problems among Italian high school students: results from a latent class analysis. J Gambl Stud 34, 339-59. [Medline] [CrossRef]

5) Hing N, Russell AM, Browne M (2017) Risk factors for gambling problems on online electronic gaming machines, race betting and sports betting. Front Psychol 8, 779. [Medline] [CrossRef]

6) Shaffer HJ, Hall MN (2001) Updating and refining prevalence estimates of disordered gambling behaviour in the United States and Canada. Can J Public Health 92, 168-72. [Medline] [CrossRef]

7) American Psychiatric Association (2013) Diagnostic and statistical manual of mental disorder (DSM-5). American Psychiatric Association, Washington DC.

8) Bruneau M, Grall-Bronnec M, Vénisse JL, Romo L, Valleur M, Magalon D, Fatséas M, Chéreau-Boudet I, Luquiens A, Challet-Bouju G, Hardouin JB, JEU-Group (2016) Gambling transitions among adult gamblers: a multi-state model using a Markovian approach applied to the JEU cohort. Addict Behav 57, 13-20. [Medline] [CrossRef]

9) Costes JM, Pousset M, Eroukmanoff V, Le Nezet O, Richard JB, Guignard R, Beck F, Arwidson P (2011) Levels and gambling practices in 2010. Lettre Tendances 77, 1-8.

10) Abbott MW, Romild U, Volberg RA (2014) Gambling and problem gambling in Sweden: changes between 1998 and 
2009. J Gambl Stud 30, 985-99. [Medline] [CrossRef]

11) Guillou-Landreat M, Guilleux A, Sauvaget A, Brisson L, Leboucher J, Remaud M, Challet-Bouju G, Grall-Bronnec M (2016) Factors associated with suicidal risk among a French cohort of problem gamblers seeking treatment. Psychiatry Res 240, 11-8. [Medline] [CrossRef]

12) Veselka L, Wijesingha R, Leatherdale ST, Turner NE, Elton-Marshall T (2018) Factors associated with social casino gaming among adolescents across game types. BMC Public Health 18, 1167. [Medline] [CrossRef]

13) Orford J, Wardle H, Griffiths M, Sproston K, Erens B (2010) The role of social factors in gambling: evidence from the 2007 British Gambling Prevalence Survey. Community Work Fam 13, 257-71. [CrossRef]

14) Lim MSM, Bowden-Jones H, Salinas M, Price J, Goodwin GM, Geddes J, Rogers RD (2017) The experience of gambling problems in British professional footballers: a preliminary qualitative study. Addict Res Theory 25, 129-38. [CrossRef]

15) Russell AMT, Langham E, Hing N (2018) Social influences normalize gambling-related harm among higher risk gamblers. J Behav Addict 7, 1100-11. [Medline] [CrossRef]

16) Hing N, Gainsbury S (2013) Workplace risk and protective factors for gambling problems among gambling industry employees. J Bus Res 66, 1667-73. [CrossRef]

17) Société Française d'Alcoologie (SFA) en partenariat avec la Société Française de Médecine du Travail (SFMT) (2013) Dépistage et gestion du mésusage de substances psychoactives susceptibles de générer des troubles du comportement en milieu professionnel. Alcool Addictol 35, 61-92.

18) Shaffer HJ, Vander Bilt J, Hall MN (1999) Gambling, drinking, smoking and other health risk activities among casino employees. Am J Ind Med 36, 365-78. [Medline] [CrossRef]

19) Gray HM, Tom MA, LaPlante DA, Shaffer HJ (2015) Using opinions and knowledge to identify natural groups of gambling employees. J Gambl Stud 31, 1753-66. [Medline] [CrossRef]

20) Petry NM, Mallya S (2004) Gambling participation and problems among employees at a university health center. J Gambl Stud 20, 155-70. [Medline] [CrossRef]

21) Phua FTT (2017) Does the built-environment industry attract risk-taking individuals? Construct Manag Econ 35, 207-17. [CrossRef]

22) Gilbert F, Richard JB, Lapie-Legouis P, Beck F, Vercambre MN (2015) Health behaviors: is there any distinction for teachers? A cross-sectional nationwide study. PLoS One 10, e0120040. [Medline] [CrossRef]

23) Revheim T, Buvik K (2009) Opportunity structure for gambling and problem gambling among employees in the transport industry. Int J Ment Health Addict 7, 217-28. [CrossRef]

24) International Commission on Occupational Health (2014) Code of Ethics. http://www.icohweb.org/site/code-of-ethics. asp Accessed July 30, 2018.

25) Johnson EE, Hamer R, Nora RM, Tan B, Eisenstein N, Engelhart C (1997) The Lie/Bet Questionnaire for screening pathological gamblers. Psychol Rep 80, 83-8. [Medline] [CrossRef]

26) Johnson EE, Hamer RM, Nora RM (1998) The Lie/Bet Questionnaire for screening pathological gamblers: a follow-up study. Psychol Rep 83, 1219-24. [Medline] [CrossRef]

27) Götestam KG, Johansson A, Wenzel HG, Simonsen IE (2004) Validation of the lie/bet screen for pathological gambling on two normal population data sets. Psychol Rep 95, 1009-13. [Medline] [CrossRef]

28) Ferris J, Wynne H (2001) Rapport final sur le CPGI (ou ICJE). The Canadian problem gambling index: Final report. Canadian Centre on Substance Abuse, Ontario.

29) Durand-Moreau Q, LE Deun C, Loddé B, Dewitte JD (2018) The framework of clinical occupational medicine to provide new insight for workaholism. Ind Health 56, 441-51 [CrossRef]. [Medline]

30) Durand-Moreau Q, Ragot A, Balez R, Alasoeur A, Passelergue JM, Guiho-Bailly MP (2014) Importance of multidisciplinary medical collaboration in occupational health: a case-report on workaholism. Arch Mal Prof Environ 75, 303-8 (in French).

31) Inserm. Jeux de hasard et d'argent: contextes et addictions. Rapport (2008) Paris: Les éditions Inserm. http://www. ipubli.inserm.fr/handle/10608/103.

32) Costes JM, Kairouz S, Monson E, Eroukmanoff V (2018) Where lies the harm in lottery gambling? A portrait of gambling practices and associated problems. J Gambl Stud 34, 1293-311. [Medline] [CrossRef]

33) Sussman S, Ames SL (2001) The social psychology of drug abuse. Open University Press, Buckinghan. https://www. mheducation.co.uk/openup/chapters/0335206182.pdf.

34) Nyman JA, Dowd BE, Hakes JK, Winters KC, King S (2013) Work and non-pathological gambling. J Gambl Stud 29, 61-81. [Medline] [CrossRef]

35) Burlacu S, Romo L, Lucas C, Legauffre C (2013) Motivation in gambling activities among French gamblers. Ann Med Psychol (Paris) 171, 410-4 (in French). [CrossRef]

36) Suris JC, Akré C, Petzold A, Berchtold A, Simon O (2011) La problématique des jeux d'argent chez les adolescents du canton de Neuchâtel. Lausanne: Institut universitaire de médecine sociale et préventive (Raisons de santé, 192). https://serval.unil.ch/resource/ serval:BIB_9CE0DA18B484.P001/REF.

37) Hartley R, Farrell L (2002) Can expected utility theory explain gambling? Am Econ Rev 92, 613-24. [CrossRef]

38) Bowden-Jones H (2017) Pathological gambling. BMJ 357, j1593. [Medline] [CrossRef]

39) Nguene Ngo MR (2015) Differentiated forms of drug use at work: the case of restaurants, bars and building sites. Psychotropes 21, 77-95 (in French). 


\section{Appendix 1. Summaries of gamblers' circumstances linking occupation and gambling.}

1. 45 yr-old man, working as a butcher on a permanent contract in a delicatessen. After completing a butchery vocational training course, he worked in cured meats and has occupied his present position for several years. His gambling is limited to sports betting. He has a positive score in the Lie or Bet, having answered yes to the second question on the perceived need to bet more and more money. His CPGI score of 6 points classifies him at "moderate risk" and therefore as a problem gambler. Although he has not gambled for 6 months, he, nevertheless, links his previous gambling to his work. His gambling first began during his apprenticeship when he gambled with his employer during work breaks. Subsequently, and particularly in his current job, this gambling continued and increased. The link with work, however, persisted in the form of gambling with colleagues during work breaks, or joint participation in sports betting. He was offered a consultation in an addiction centre and at the Occupational Diseases Centre, which he refused because he was already seeing a therapist and he has currently stopped gambling.

2. 34 yr-old woman, working as a pharmacy technician, currently on a permanent contract. She has a level of $2 \mathrm{yr}$ higher education with a professional diploma as a pharmacy technician. She describes herself as an occasional gambler, playing scratch games only a dozen times a year and also going to the casino once a year. Her gambling involves small sums of money and is not experienced as problematic. She responded negatively to the two Lie or Bet questions. Despite this non-problematic and occasional gambling, she links her gambling to her work, stating that, if she did not work, she would not have any money to spend on gambling.

3. 19 yr-old woman, working as a general food services employee on a permanent contract for a large fast-food chain. Currently, she only has the school leaving certificate. She states that she gambles scratch cards, at least once a week, always with small sums of money. She responded positively to the first question of the Lie or Bet about lying to her family concerning her gambling behavior. With one point on the CPGI, she is classified as "low risk". The link she sees between her gambling and her work is that she "has to earn money to be able to gamble". She also stated that she would gamble even if she were unemployed or whatever job she did. She also reported other elements related to her behavior, such as feeling the need to gamble.

4. 55 yr-old man, barman on a permanent contract in a bar-tobacco shop for many years. He has no diploma other than the school leaving certificate. He regularly gambles on point-of-sale games. However, he responded negatively to the Lie or Bet. This gambling is not experienced by the employee as negative. The link he sees between his work and his gambling is simple. His job includes selling gambling products. In this context, he gambles once a week with regular customers, always the same amount.

5. 23 yr-old woman, clothing sales assistant on a permanent contract in a women's clothing store. She has a Baccalaureate in sales. She states that she gambles weekly on lotteries and regularly gambles on scratch cards. She responded positively to the Lie or Bet second question and, with 2 points, she is classified as "low risk" by the CPGI. The link she sees between her gambling and her work is that she gambles to make a little extra money each month, as her job is not well-paid.

6. 51 yr-old man, electro-mechanic on a permanent contract in an industrial equipment installation and maintenance company. He has a vocational training certificate in electro-mechanics. He admits occasionally gambling on the Loto $^{\circledR}$ and scratch games. He responded negatively to the Lie or Bet. He states that he only gambles with his colleagues, and furthermore, when they gamble on the Loto ${ }^{\circledR}$, they bet as a syndicate. He also specifies that he does not gamble outside these moments of camaraderie with his colleagues.

7. 56 yr-old man, client manager on a permanent contract in a bank for several years. He holds a Master's degree in Economics and Management. He gambles from time to time on the Loto ${ }^{\circledR}$ and responded negatively to the two Lie or Bet questions. He admits gambling only with his colleagues, betting 2 Euros in the pool for the lottery "super jackpots". According to him, he participates in these games with colleagues for the sake of "team spirit", specifying that not playing would amount to isolating himself from his colleagues.

8. 48 yr-old woman, commercial manager on a permanent contract in a different bank from that of the previous case. She has a 2 yr higher education qualification in banking. She admits gambling on the Loto ${ }^{\circledR}$ "super jackpots" and 
twice a year on scratch games. She responded negatively to the two Lie or Bet questions. Although she gambles on scratch cards outside of work, in the case of the lotteries, she gambles with her colleagues for the "super jackpots". The link she sees between her gambling and her work is related to the lotteries. She describes this participation as normal among colleagues.

9. 41 yr-old woman, home help for a personal assistance company on a permanent contract. She has a vocational training certificate in cooking. She gambles weekly on lotteries and responded negatively to the Lie or Bet. The link she sees between her gambling and her work is that, having an irregular work schedule, she often has one to two hours during the day when she is not working, and during this time, in order to limit her journeys, she waits in a bar. These times spent waiting in a place with easy access to gambling led the employee to make the link between her gambling and her work. The employee works outside her town of residence, going to private houses as part of her job. However, the journeys reimbursed by her company during these break times, a total of one $h$, are those from one patient to another. Thus, it is less costly to spend this waiting time in her clients' towns, rather than go home where she could stay only a short time.

10. 24 yr-old man, waiter on a permanent contract in a bar-restaurant where the employer is also the father of the employee. He has a Baccalaureate in the hotel trade. He bets weekly on sports and responded negatively to the Lie or Bet. He makes these sports bets with his clients during and after working hours, only when he is on duty at the bar. He never gambles alone or outside working hours. This gambling is experienced as non-problematic by the employee.

11. 28 yr-old woman, waitress on a permanent contract in a bar-tobacconist's for the past two years. She has a Baccalaureate in the sales sector. She admits gambling regularly on scratch games, lotteries, online poker and sports betting. She responded positively to the two Lie or Bet questions and presents a "low risk" on the CPGI, with a score of one point. She sees a link between her gambling behavior and her work. She gambles at her place of work but specifies that she does not go back during her holidays to gamble. However, she gambled before working in this position and she says that she gambles with her partner. The gambling described during the interview is important. In particular, she described difficulties in giving up this gambling. The contact information of the addiction centre was given to the employee.

12. 23 yr-old woman, waitress on a 6-month fixed-term contract in a bar. She has a Baccalaureate in the sales sector. She admits gambling regularly on scratch games. The Lie or Bet was positive, with a positive answer to question number 2 on the perceived need to bet more and more money. The CPGI, with a score of one point, categorizes the employee as "low risk". Since her recruitment 2 months ago, she sees a link between her gambling and her work. Indeed, this behavior started at work because of the ease of access to gambling and what she describes as part of her job in testing the new games that she offers to customers. 